\title{
Technology and You: Working with the Aerospace Industry to Enhance Engineering Education
}

\author{
Russell M. Cummings* \\ United States Air Force Academy, USAF Academy, CO, 80840 \\ John H. McMasters \\ The Boeing Company, Seattle, WA, 98124
}

\begin{abstract}
While many engineers in the aerospace engineering profession know that interacting with students is a good idea, few of them know how to do it. Certainly some engineers are asked on occasion to give lectures at various university club meetings, and some are even heavily involved in interacting with students working on various design projects, but the average engineer has little or no interaction with students over the course of their career. A number of companies, including Boeing, have created technical interest groups to encourage mentoring and sharing of corporate knowledge throughout the company. These efforts have been met with varying degrees of success. In an effort to improve this situation, the Boeing Technology Interest Group concept has been modified and expanded to include students within the groups. Concepts for including students (both graduate and undergraduate) and faculty are discussed, including details about how the concept could be integrated into existing research and educational programs. Conclusions are drawn about the feasibility of the concept and suggestions for implementation are made.
\end{abstract}

\section{Introduction}

$\mathrm{T}$ HE concept of a guild dates from medieval times, where merchants and craftsman formed loose associations for the continuance and improvement of their professional interests. While merchant guilds were primarily created to protect trade and commerce, the craft guilds were created to protect the skills and knowledge that would insure the continuance of the craft. The guild concept has had a centuries-long influence on how people in certain trades are trained. Guilds, among other things, offered younger members the ability to participate in a small group of people who had a shared ability or skill (such as being woodworkers or blacksmiths). The new "member" of the guild would attach themselves to a more experienced member as an apprentice, as shown in Fig. 1. While interacting with the journeyman (skilled but still learning) and/or master (highly skilled and mentoring), the apprentice would learn not only the technical

\footnotetext{
* This work was accomplished while a Professor of Aerospace Engineering at California Polytechnic State University in San Luis Obispo, CA.
} 
aspects of their job (which tools to use for what purposes), but they would also gain understanding about when to use those tools (and when to not use the tools!).

"The guild tended to be an extremely hierarchical body structured on the basis of the apprenticeship system. In this structure, the members of a guild were divided into a hierarchy of masters, journeymen, and apprentices. The master was an established craftsman of recognized abilities who took on apprentices; these were boys in late childhood or adolescence who boarded with the master's family and were trained by him in the elements of his trade. The apprentices were provided with food, clothing, shelter, and an education by the master, and in return they worked for him without payment. After completing a fixed term of service of from five to nine years, an apprentice became a journeyman, i.e., a craftsman who could work for one or another master and was paid with wages for his labour. A journeyman who could provide proof of his technical competence (the "masterpiece") might rise in the guild to the status of a master, whereupon he could set up his own workshop and hire and train apprentices. The masters in any particular craft guild tended to be a select inner circle who possessed not only technical competence but also proof of their wealth and social position. Apprenticeship was the basic element in the craft guild, since it secured the continuity of practice, tradition, and personnel on which the welfare of the guild depended."1

As time went on for the apprentice, they could gain journeyman status and begin mentoring some new apprentice, thus handing down the skills, knowledge, and understanding they had acquired. By working hand in hand over a long period of time, the apprentice would be able to achieve an improved status through hard working, listening, and doing.

As time went on and our societies became more industrialized, there was less and less need for anyone to be so highly trained in a skill, since machines and factories could out-produce the human hand (in quantity if not in quality). Eventually, the concept of the guild was largely lost, although it still existed to some extent with certain trades such as carpentry, plumbing, and horse shoeing. While the guild concept dwindled in popularity, many people realized that there were certain characteristics of a guild that were valuable today, even in non-trade professions such as engineering. Many of the guild characteristics have been recently rediscovered within a concept known as a "community of practice" by Wegner. These communities exist within a variety of professions, including Chrysler's Technology Clubs among other. But what is a community of practice?

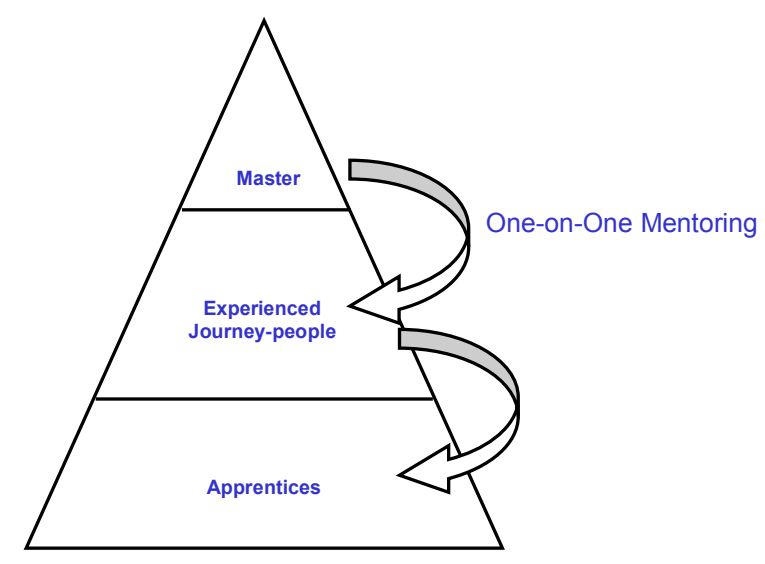

Figure 1. The Craft Guild Concept. 
There are three essential characteristics to a community of practice: ${ }^{2}$

- "The domain

○ not merely a club of friends or a network of connections between people

$\circ$ an identity defined by a shared domain of interest

- membership implies a commitment to the domain, and a shared competence that distinguishes members from other people

- The community

- members engage in joint activities and discussions, help each other, and share information

○ build relationships that enable them to learn from each other

- members of a community of practice do not necessarily work together on a daily basis (example: The Impressionists)

- The practice

- members of a community of practice are practitioners

$\circ$ they develop a shared repertoire of resources: experiences, stories, tools, ways of addressing recurring problems - in short a shared practice

o this takes time and sustained interaction"

This definition extends the guild concept beyond just a mentor/mentoree relationship, and even beyond the scope of the guild itself. Instead of just providing a method for transferring knowledge and maintaining standards, the community of practice becomes a group with a shared interest in a knowledge domain, regardless of whether all of the members work together or not. These aspects of the community of practice provide an interesting and important background for the Technology Interest Group concept.

\section{The Boeing Technology Interest Group Concept}

The Boeing Company has added some original and interesting aspects to their take on Communities of Practice, primarily based on their need to consolidate a number of companies they acquired into a single, global aerospace corporation (see Fig. 2). If you just consider the aircraft (both commercial and military) side of the Boeing house, there were design groups at a number of locations around the country with different approaches, processes, methods, and histories regarding air vehicle design. How could these divers groups be brought together in a positive way? A number of approaches were taken, including the creation of the Technical Fellowship (as a "career path" alternate to promotion into management), of which the Technology Interest Groups (TIGs), are a means of sharing practices and processes throughout the company.

Boeing created the Technical Fellowship both as a way to honor technical excellence within the company, and as a way for technical experts from

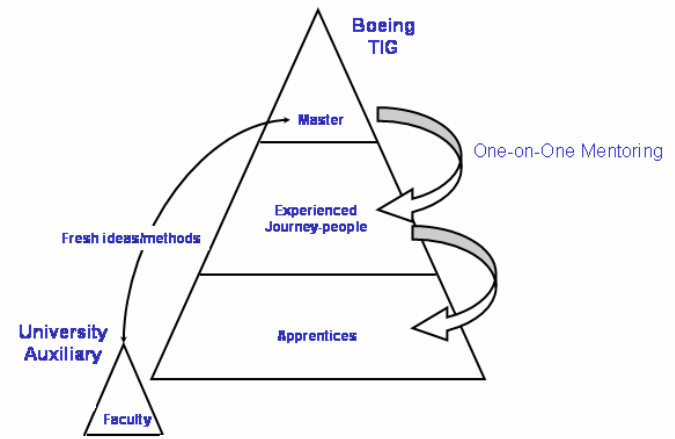

Figure 2. The Boeing Technology Interest Group Concept. 
one part of the company to communicate with experts from another part of the company. Best practices, new concepts, cutting-edge research, and novel approaches could all be shared among these experts. Bringing together this highly talented group of people also led to innovative ideas about how to improve corporate communication even more, including the creation of Technology Interest Groups.

Boeing realized that aerospace vehicles remain a core of their business structure, in spite of rapid growth in a variety of other business areas (especially space and communications). As has been seen in all industries within the United States, a large retirement bubble was looming on the landscape as the aircraft designers and engineers who had joined the company in the 1960s began to retire, and with their retirement came a large "brain drain" of knowledge, understanding, and even wisdom about how to approach aircraft design. All the excellent technology and processes in the world would be useless without the necessary skilled and motivated people to apply them to new designs and concepts. In addition, it had become apparent over the years that talented designers are hard to come by (and even harder to define!). However, it was obvious that the skill needed to be a good designer would have to be cultivated among lower and middle level engineers, or there would be no design talent left in the company within a fairly short period of time.

The Technology Interest Groups were formed, therefore, to pursue the achievement of the following goals:

- aid in retention and enhancement of skills and knowledge in key technologies (present and future)

- share information, knowledge and experience across the enterprise

- provide mentoring, training and networking opportunities for those at all experience levels

- create a sense of community - instill pride and enhance morale

- bring into the company new ideas, methods and knowledge from the wider technical community (academe, etc.)

- develop clear, vivid visions (roadmaps) of key technologies - present and future - and the context within which they are applied (to aid recruiting, technology planning, etc.)

These goals hold incredible potential for making the technical side of the company vital and exciting, giving younger engineers and scientists a viable career path for success and promotion without having to go into the management side of the business. Some of the essential elements of making the TIG concept work include:

- membership must be open to anyone (including managers, etc.) at all levels of experience - based solely on interest and willingness to participate

- participation in more than one TIG is encouraged (especially important for cross fertilization (aerodynamics and structures, etc.)

- knowledge sharing within and across TIG boundaries is obligatory throughout the enterprise

- mentorship is an intrinsic element of TIG activity 


\section{The Modified TIG Concept}

While the TIG concept seemed an excellent way to promote shared knowledge among various portions of a large, diverse corporation, several improvements could be made to expand the concept beyond a purely technical organization. The most important extension was to expand the Technology Interest Group concept to the university in order to enhance relations between the company, faculty, and students, as shown in Fig. 3. The basic idea was to use an Aircraft Design course as the foundation and testing ground for the university "auxiliary", since aerospace is a truly multidisciplinary discipline, so all majors could participate via their interest in aerospace. Eventually the concept could be expanded across the engineering disciplines by allowing universities access to the various TIGs formed in the company.

The extension of the TIG to universities could benefit both the company and academia. The company could benefit from the flow of new ideas, concepts, and research to Boeing from academia. At the same time, the flow of design concepts, methods, and approaches from Boeing to academia could improve curriculum and

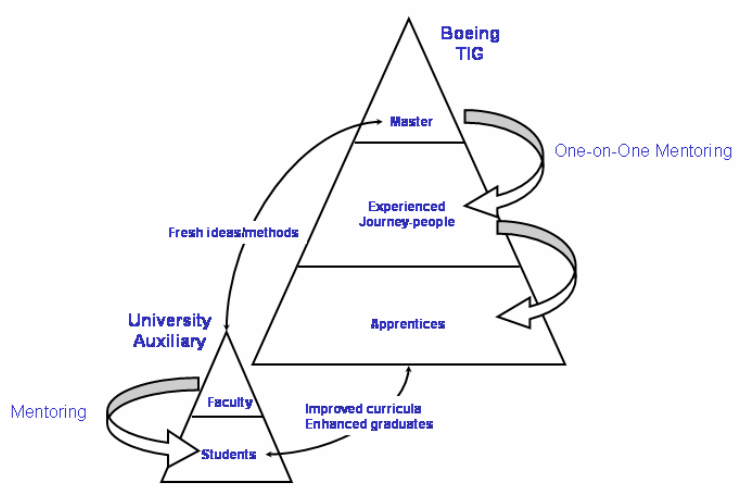

Figure 3. The Modified TIG Concept. enhance the graduates of the university. This provided a company the chance to influence engineering education, especially in areas that the company cares about the most.

\section{A Comprehensive TIG Concept}

Finally, the Boeing TIG concept could be envisioned to grow well beyond that shown in Fig. 3, in fact, it could grow to incorporate the entire corporation (not just local technical leads with interests in individual universities) as well as multiple universities, as shown in Fig. 4. This "Comprehensive TIG Concept" could be considered as the vehicle for making TIGs truly workable and universal.

Instead of seeing each university as an unattached entity, the comprehensive TIG concept would encourage universities to work together (or in competition with one another) on a variety of new aircraft challenges, such as:

- Mini RPVs

- Robotic aircraft

- Fire-fighting aircraft

- Mars airplanes

- Other interesting aircraft as determined by Boeing's interests 


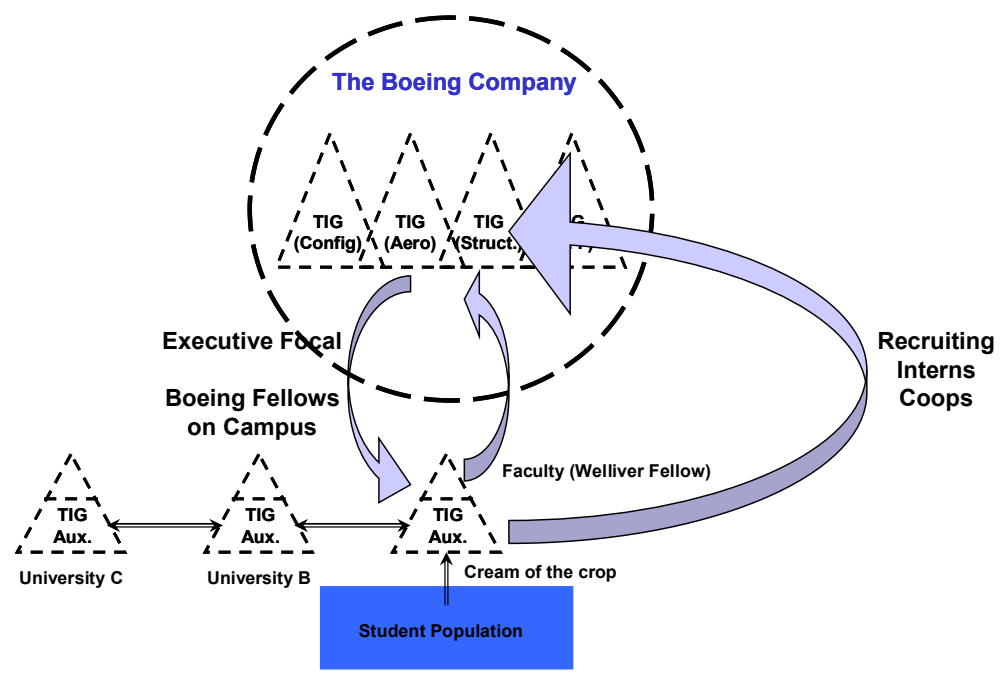

Figure 4. A Comprehensive TIG Concept.

The students involved in the program would be required to work through the conceptual design process, including:

- examine markets, needs, requirements, etc.

- brainstorm configuration candidates

- evaluate candidates based on initial criteria and downselect

- analyze final candidates

- choose final candidate for preliminary design

- cycle through designs fairly rapidly to provide the greatest possible experience

Trickle Down, Grow Up

In addition to the technical knowledge learned by the students, a variety of opportunities for mentoring would become available, including: lower-classmen undergraduates could learn about the variables in an airplane design (high/mid/low wing, etc.), study historical aircraft (good and bad), and learn to perform trade studies. Upperclassmen undergraduates could study creative designs, learn to brainstorm new design ideas, and understand the inter-connections between design variables and resulting aircraft capabilities. Finally, graduate students would learn to perform

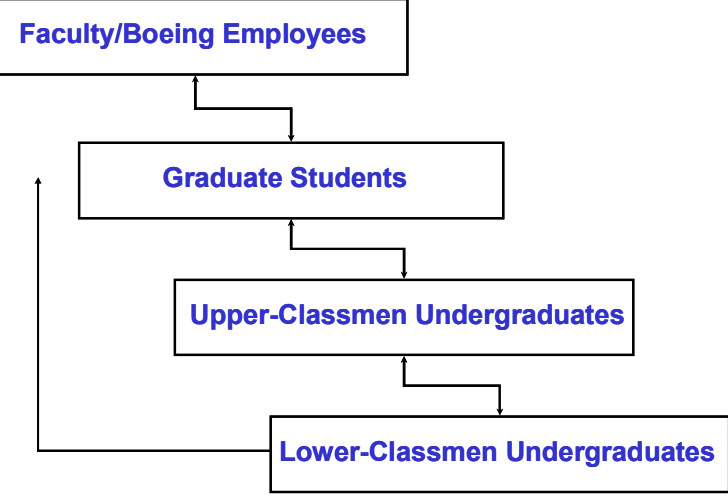

Figure 5. The Trickle Down/Grow Up Concept. preliminary design studies and balance complex systems within the design. On top of all of this would be the faculty and engineers from industry who could provide guidance and knowledge to the students as they progressed through their designs. We refer to this as the Trickle Down/Grow Up concept (see Fig. 5), since the mentored 
students would also be learning to mentor others in the future, leading to engineers who would be better able to function on the design of complex aerospace systems in the future.

\section{Implementation}

Boeing implemented and has been using the TIG concept for many years, primarily within the context of their Technical Fellowship program. As was mentioned earlier, the Technical Fellowship is a means within Boeing to provide a technical career path alternate management, providing technically-interested employees a means to achieving success without having to give up their technical pursuit. The Technology Interest Groups allow the Technical Fellowship a way to coordinate and mentor other employees with similar interests and pursuits.

Some issues for successful operation of the TIGs have become apparent in the past years. The issues come from a variety of perspectives, and show that the entire company must be committed to the TIG concept in order to insure its success:

- Management Challenge

o focus on topics important to the business and community members

$\circ$ find a well-respected community member to coordinate the community

- make sure people have time and encouragement to participate

$\circ$ build on the core values of the organization

- Community Challenge

o get key thought leaders involved

$\circ$ build personal relationships among community members

- develop an active, passionate core group

o create forums for thinking together as well as systems for sharing information

- Technical Challenge

$\circ$ make it easy to contribute and access the communities knowledge and practices

- Personal Challenge

○ create a real dialogue about cutting edge issues

As can be seen, all phases of the company are essential to the success of the TIGs, but all phases of the company also have a personal stake in insuring that the TIGs thrive and grow. Another important lesson learned is that TIGs seem to work best for topics for which there is no single organizational home (e.g. Process Engineering) or for topic areas that are so new that it is not well recognized in the traditional system.

While the university auxiliaries for the TIG have not been formally implemented, a closelyrelated concept is being used at California Polytechnic State University (Cal Poly) at San Luis Obispo. Following closely on the heels of the first authors time as a Boeing A.D. Welliver Faculty Summer Fellow, Cal Poly began a design course for sophomore students in aeronautical engineering. ${ }^{3}$ This course allows second-year students to "try their hand" at design, in spite of the fact that they do not have all of the technical skills necessary to analyze their work. Engineers from Boeing have been instrumental in supplying real-world design projects for this course, and have been intimately involved in mentoring students and critiquing their work. To see a group of sophomores present aircraft designs to engineers from the aerospace industry and to realize that they could contribute knowledge and ideas to solving real-world problems is 
inspiring, to say the least! Cal Poly's senior-level design course has been taking advantage of similar concepts for many years, 4 and has found that the involvement of industry engineers throughout the design process has been invaluable to the success of the year-long design course, as evidenced by their success in the AIAA Team Aircraft Design competition. While a great deal more can be done with the TIG concept, especially at the university level, we have only scratched the surface with these early attempts at making TIGs workable for students, faculty, and engineers in the aerospace industry.

\section{Conclusions}

A variety of methods for "communities of practice" to interact within the engineering and academic worlds have been discussed. These include the original Boeing concept of a Technology Interest Group (TIG), as well as several extensions to the concept that include faculty member and students working on projects of interest to the aerospace community. Several benefits of these expanded TIG concepts include: 1) improved relations between the engineering industry and academia, 2) more involvement of faculty in real-world engineering problems and solution methods, 3) improved education of engineering students, and 4) an opportunity for mentoring at a variety of levels from the engineering industry down to the newest Freshman at a college campus. These ideas are meant to serve as discussion items at this time, since only the most basic attempts at implementation have been undertaken. Interested people are welcome to take these ideas and expand them, evolve them, and grow them into ways to improve engineering education.

\section{References}

${ }^{1}$ Encyclopcedia Britannica, 2004, Encyclopædia Britannica Online, 17 Nov. 2004, http://search.eb.com/eb/article?tocId=9038409.

${ }^{2}$ Wenger, E., Cultivating Communities of Practice: A Guide to Managing Knowledge, Boston: Harvard Business School Press, 2002.

${ }^{3}$ Cummings, R.M. and D.W. Hall, “Aircraft Design for Second-Year Undergraduate Students,” International Journal of Engineering Education, Vol. 21, No. 1, 2005.

${ }^{4}$ Cummings, R.M. and H.J.A. Freeman, "Integrating Multidisciplinary Design in an Undergraduate Engineering Curriculum," SAE Transactions, Vol. 106, No.1, 1997, pp. 1665-1670.

\section{Biographies}

\section{RUSSELL M. CUMMINGS}

Dr. Cummings graduated from California Polytechnic State University with a B.S. and M.S. in Aeronautical Engineering in 1977 and 1985, respectively, before receiving his Ph.D. in Aerospace Engineering from the University of Southern California in 1988. He was recently named Professor of Aeronautics at the U.S. Air Force Academy and previously was Professor of Aerospace Engineering at Cal Poly from 1986 through 2004.

\section{JOHN H. McMASTERS}

Dr. McMasters joined Boeing Commercial Airplanes in 1976 as a research aerodynamicist, and currently serves as a program manager for the Ed Wells Initiative, a joint program between Boeing and the Society of Professional Engineering Employees in Aerospace charged with enhancing the excellence of the SPEEA represented Boeing technical workforce. He also is a member of the Boeing University Relations Process Council and has served since 1990 as an Affiliate Professor in the Department of Aeronautics and Astronautics at the University of Washington. 